\title{
Metabolic modeling of synthesis gas fermentation in bubble column reactors
}

\author{
Jin Chen ${ }^{1}$, Jose A. Gomez ${ }^{2}$, Kai Höffner ${ }^{2}$, Paul I. Barton ${ }^{2}$ and Michael A. Henson ${ }^{1 *}$
}

\begin{abstract}
Background: A promising route to renewable liquid fuels and chemicals is the fermentation of synthesis gas (syngas) streams to synthesize desired products such as ethanol and 2,3-butanediol. While commercial development of syngas fermentation technology is underway, an unmet need is the development of integrated metabolic and transport models for industrially relevant syngas bubble column reactors.

Results: We developed and evaluated a spatiotemporal metabolic model for bubble column reactors with the syngas fermenting bacterium Clostridium ljungdahlii as the microbial catalyst. Our modeling approach involved combining a genome-scale reconstruction of C. ljungdahlii metabolism with multiphase transport equations that govern convective and dispersive processes within the spatially varying column. The reactor model was spatially discretized to yield a large set of ordinary differential equations (ODEs) in time with embedded linear programs (LPs) and solved using the MATLAB based code DFBAlab. Simulations were performed to analyze the effects of important process and cellular parameters on key measures of reactor performance including ethanol titer, ethanol-to-acetate ratio, and CO and $\mathrm{H}_{2}$ conversions.

Conclusions: Our computational study demonstrated that mathematical modeling provides a complementary tool to experimentation for understanding, predicting, and optimizing syngas fermentation reactors. These model predictions could guide future cellular and process engineering efforts aimed at alleviating bottlenecks to biochemical production in syngas bubble column reactors.
\end{abstract}

Keywords: Metabolic modeling, Bioprocess engineering, Microbial fermentation, Ethanol production

\section{Background}

The development of alternative, renewable sources of fuels and chemicals to reduce our dependence on petroleum has emerged as a paramount challenge for maintaining the economic security and environmental wellbeing of the USA. An essential component of this quest is to develop renewable, environmentally friendly sources of biochemicals via the conversion of readily available plant biomass and waste streams that represent a significant quantity of reduced carbon feedstock. An emerging conversion route with wide feedstock versatility is direct fermentation of waste gas streams and synthesis gas (syngas; mainly comprised of $\mathrm{H}_{2} / \mathrm{CO} / \mathrm{CO}_{2}$ ) by specialized $\mathrm{CO}$ fermenting microbes. Because syngas can be produced relatively cheaply from a wide variety of biomass feedstocks $[1,2]$,

\footnotetext{
* Correspondence: henson@ecs.umass.edu

${ }^{1}$ Department of Chemical Engineering, University of Massachusetts, Amherst, MA 010003, USA

Full list of author information is available at the end of the article
}

the bottleneck in this route is the syngas fermentation step. Key considerations are the metabolic capabilities and performance of the microbial catalyst that converts syngas into the desired biochemical, gas-liquid mass transfer characteristics that determine the availability of soluble gas components for microbial conversion and the bioreactor design that affects all aspects of the conversion process.

\section{Gas fermentation for production of fuels and chemicals} A model syngas-consuming organism is Clostridium ljungdahlii, a rod-shape anaerobic bacterium that was discovered in 1987 and found to have the ability to ferment $\mathrm{CO}$ and $\mathrm{H}_{2}$ into ethanol and acetate [3]. This discovery initiated a wave of research and development efforts aimed at understanding and optimizing syngas fermentation for ethanol production [4]. Several other bacteria including C. aceticum [5], Acetobacterium woodii [6], and C. carboxidivorans [7] also have been studied for 
syngas fermentation. All these mesophilic bacteria synthesize ethanol through the reductive acetyl-CoA metabolic pathway, a non-cyclic, fermentative pathway which is active under anaerobic conditions [8]. Electrons required in the pathway are supplied by the syngas components $\mathrm{CO}$ and $\mathrm{H}_{2}$. Optimal growth conditions for C. ljungdahlii have been reported as $37^{\circ} \mathrm{C}$ and $\mathrm{pH}$ of 6.0 [9], but at least one study claims that ethanol synthesis was increased at lower $\mathrm{pH}$ values where growth was significantly reduced [10].

One of the most challenging problems in syngas fermentation is to establish culture conditions which offer favorable gas-liquid mass transfer characteristics such that the syngas is readily dissolved and available for microbial conversion. A variety of reactor types including stirred tank reactors, trickle bed reactors, packed bed reactors, monolithic biofilm reactors, membrane-based reactors, and bubble column reactors have been investigated [9]. While more advanced designs based on bubble column reactors are being developed for large-scale production [8], most academic research has been performed in stirred tank reactors with continuous liquid and syngas flows. Stirred tank reactors can have CO mass transfer coefficients over $100 \mathrm{~h}^{-1}$ through the use of specially designed impellers, high agitation rates, and microspargers that create small gas bubbles $[9,11]$. However, substantially enhanced syngas mass transfer can be achieved in bubble column reactors due to higher average mass transfer driving forces caused by favorable gas composition spatial profiles and longer gas-liquid contact times. Another potential strategy for increasing syngas solubility is the use of elevated operating pressures [12]. This approach has not been widely studied because gas compression at the industrial scale is costly.

Because the syngas feed is introduced into the bottom of the bubble column (Fig. 1), $\mathrm{CO}$ and $\mathrm{H}_{2}$ concentrations decrease as the gas flows up the column due to cellular consumption. Therefore, the column has spatially varying dissolved gas concentrations that affect cellular growth and product synthesis. In principle, high dissolved $\mathrm{CO}$ concentrations throughout the column are desirable since $\mathrm{CO}$ is the primary carbon source for growth. Previous experimental studies $[8,13]$ have suggested that high dissolved $\mathrm{CO}$ levels can inhibit both $\mathrm{CO}$ and $\mathrm{H}_{2}$ uptake rates (Fig. 2). Therefore, column optimization requires that dissolved $\mathrm{CO}$ concentrations are sufficiently high near the top of the column to promote growth, but $\mathrm{CO}$ concentrations near the bottom of the column are not so high as to significantly inhibit gas uptake rates. The relative amounts of dissolved $\mathrm{CO}$ and $\mathrm{H}_{2}$ have a strong impact on the split between the desired product ethanol and the undesired byproduct acetate $[14,15]$. While ethanol synthesis is promoted at high $\mathrm{H}_{2}$ concentrations, the ratio of ethanol to acetate increases

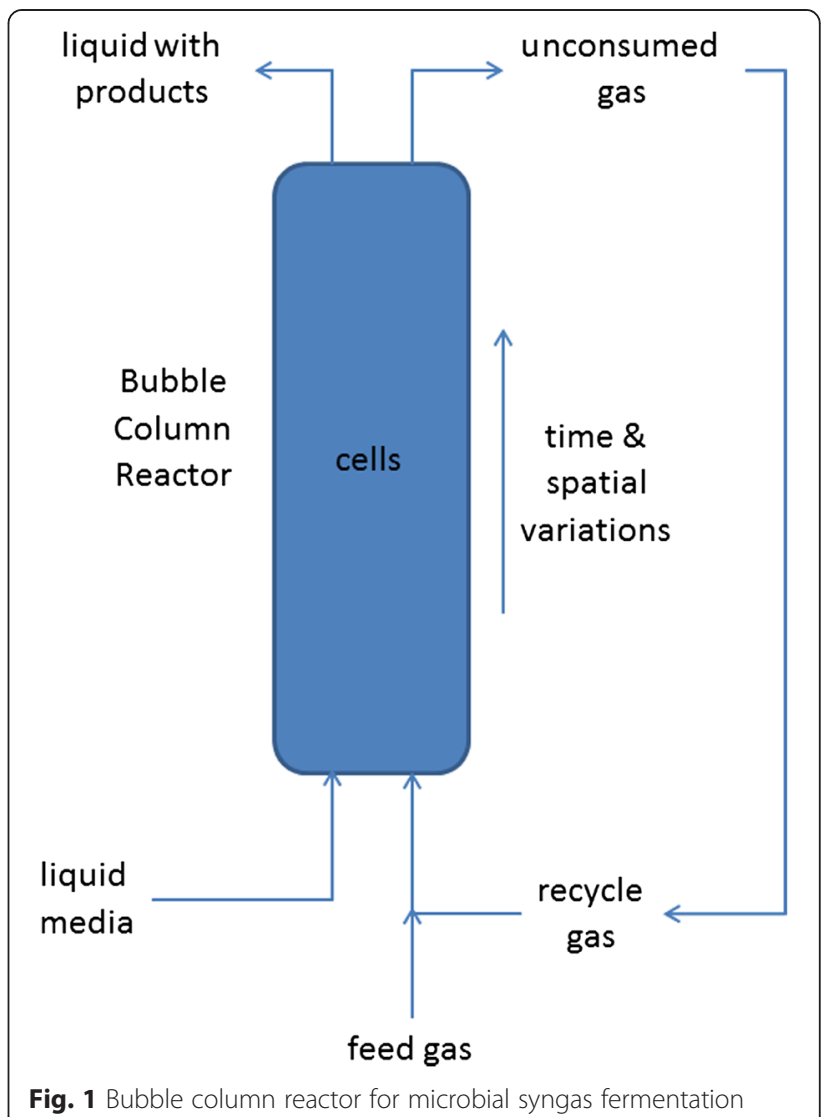

with increasing $\mathrm{H}_{2}$ concentration. Therefore, the objective is to establish desirable $\mathrm{H}_{2}$ and $\mathrm{CO}$ concentration profiles along the column such that the ethanol production is maximized and the acetate production is minimized. The design and operation of bubble column reactors to achieve a suitable compromise between these competing objectives has proven to be a difficult challenge that has limited commercial syngas fermentation technology. We believe that the development of modelbased techniques for simulating and optimizing syngas bubble column reactors is essential to advance this technology.

\section{Spatiotemporal modeling of microbial metabolism}

Steady-state [16] and dynamic [17-20] flux balance analysis techniques based on genome-scale metabolic reconstructions have become standard tools for analyzing microbial metabolism. Recently, the first genome-scale metabolic reconstruction of a $\mathrm{CO}$ fermenting organism was introduced for the bacterium C. ljungdahlii [21]. The iHN637 model includes an extensive reaction network of central metabolism, including the pathways involved in carbon fixation and energy conservation. The model was shown to be capable of producing acetate, ethanol, and 2,3-butanediol under conditions consistent with 


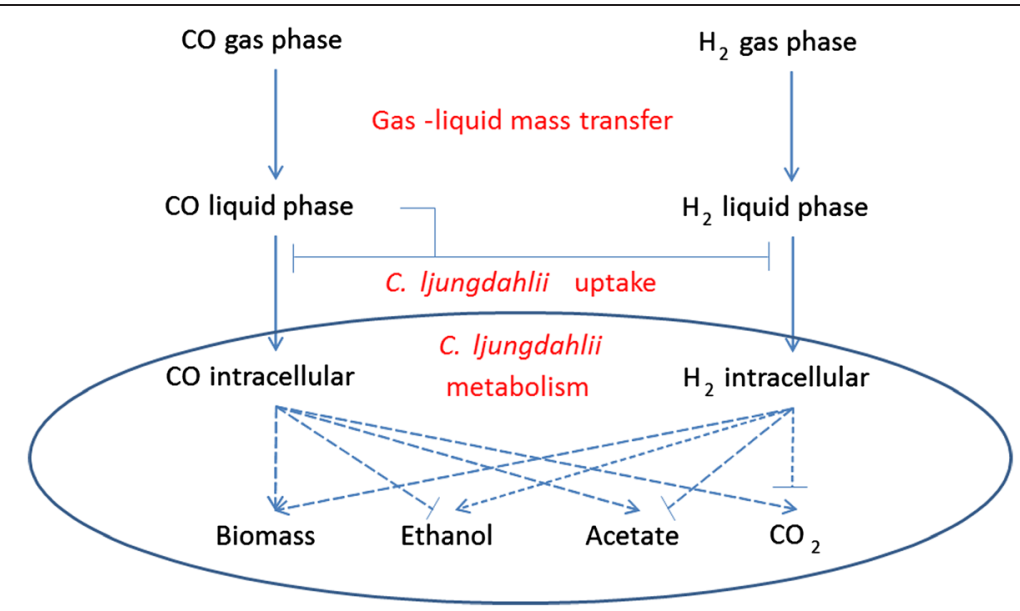

Fig. 2 The effects of $\mathrm{CO}$ and $\mathrm{H}_{2}$ mass transfer and cellular uptake on biomass production and the distribution of metabolic products by $\mathrm{C}$. ljungdahlii. The lines with arrows represent positive/activating effects and the lines with bars represent negative/inhibitory effects

experimental data. While a few very simple unstructured growth models of syngas fermentation have been developed [22, 13], we are not aware of any dynamic models based on FBA and/or genome-scale metabolic reconstructions.

Dynamic modeling of syngas bubble column reactors poses an additional challenge not encountered in wellmixed stirred tank reactors. Namely, spatial gradients are present because the dissolved $\mathrm{CO}$ and $\mathrm{H}_{2}$ concentrations decrease as the gas flows up the column due to cellular consumption [8]. The cellular growth and product synthesis rates along the column are determined by these local dissolved gas concentrations. While spatiotemporal models that account for both spatial and temporal variations in the extracellular environment have been constructed, these studies utilized table lookups of precomputed FBA solutions [23-25] or heuristic lattice-based descriptions of nutrient diffusion [23-25]. We propose a general methodology for spatiotemporal metabolic modeling based on combining genome-scale reconstructions with fundamental transport equations that capture the relevant convection and/or diffusional processes. Additional details on the numerical solution procedure will be available in a forthcoming publication. The model solution procedure involved spatially discretizing the partial differential equations (PDEs) to generate an ordinary differential equation (ODE) system with embedded linear programs (LPs) that was integrated with DFBAlab [26], a MATLAB code that performs reliable and efficient dynamic FBA simulations. We demonstrated the capabilities of our approach by performing dynamic simulations with the syngas bubble column reactor model presented below. The contributions of the present study include the following: (1) a detailed presentation of the bubble column model including experimentally derived parameters and
(2) an extensive investigation into the effects of process and cellular parameters on bubble column performance.

\section{Results and discussion}

Impact of design and operating parameters on bubble column performance

The model was used to predict the effects of important design and operating parameters on bubble column performance, as measured by the liquid and gas phase concentrations exiting the reactor under steady-state conditions. Due to the lack of accurate dissolved gas uptake kinetic parameters and directly comparable experimental data for model validation, the model predictions should be viewed as qualitative rather than quantitative. This capability was deemed sufficient for predicting trends with respect to key parameters. Each prediction was generated by simulating bubble column startup with $N=100$ node points and a final time of $1000 \mathrm{~h}$ to obtain the steady-state solution. Typically 5-10 simulations were performed for each parameter, and plots showing parameter trends were generated by linearly interpolating the cases ran (indicated by asterisks) within MATLAB.

We first investigated the impact of the feed composition by varying the $\mathrm{CO}$ mole fraction with the $\mathrm{H}_{2}$ mole fraction adjusted such that the mole fractions summed to unity. Experimental studies [27] have shown that ethanol synthesis is favored relative to acetate synthesis at high $\mathrm{H}_{2} / \mathrm{CO}$ feed ratios. We observed the same trend in our bubble column simulations (Fig. 3). The ethanol titer was predicted to achieve a maximum of $120 \mathrm{~g} / \mathrm{L}$ at a $\mathrm{CO}$ mole fraction of 0.45 , which represents a $\mathrm{H}_{2}$ rich feed. As the mole fraction was increased beyond this value, the ethanol concentration was predicted to decrease and acetate synthesis began. The ethanol and 

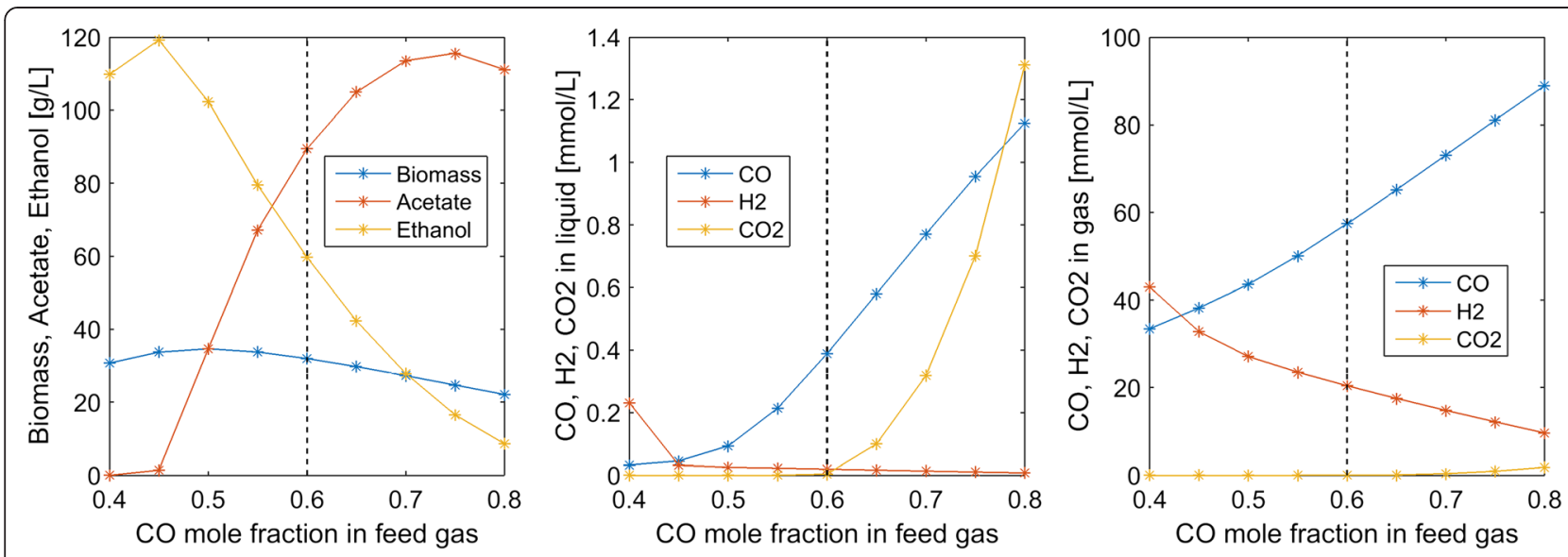

Fig. 3 Effect of the feed CO mole fraction on steady-state concentrations in the exiting liquid and gas streams. The dashed lines indicate the nominal feed CO mole fraction used in the other simulations

acetate concentrations were approximately equal at a mole fraction of 0.55 . Thereafter, the acetate titer increased rapidly, the ethanol titer decreased rapidly, and $\mathrm{CO}_{2}$ synthesis began due to low dissolved $\mathrm{H}_{2}$ levels. Interestingly, the acetate concentration decreased at $\mathrm{CO}$ mole fractions beyond 0.75 , presumably due to reduced biomass production. A maximum biomass concentration of about $35 \mathrm{~g} / \mathrm{L}$ was predicted for a 50/50 $\mathrm{CO} / \mathrm{H}_{2}$ mixture.

Next we explored the impacts of the superficial gas velocity $\left(u_{G}\right)$ reactor performance. Increasing $u_{G}$ also caused the gas volume fraction $\varepsilon_{G}$ to increase according to Eq. 9. High $u_{G}$ values were predicted to increase dissolved $\mathrm{CO}$ and $\mathrm{H}_{2}$ concentrations at the expense of reduced $\mathrm{CO}$ and $\mathrm{H}_{2}$ conversions in the gas phase (Fig. 4). Due to enhanced dissolved $\mathrm{H}_{2}$ concentrations, high $u_{G}$ values produced more favorable ethanol/acetate splits.
For example, $u_{G}=300 \mathrm{~m} / \mathrm{h}$ produced an ethanol/acetate ratio of $10: 1$ but $\mathrm{CO}$ and $\mathrm{H}_{2}$ conversions of only 7 and $19 \%$, respectively. Conversely, low $u_{G}$ values produced more favorable conversions but high acetate concentrations as well as substantial $\mathrm{CO}_{2}$ synthesis.

Many experimental studies have argued that the efficiency of syngas fermentation is limited by gas-liquid mass transfer [28]. To explore this claim, we varied the CO gas-liquid mass transfer coefficients $k_{m, C}$ to cover a range of values reported in the literature [9]. As with our nominal values, we set the $\mathrm{H}_{2}$ mass transfer coefficient $k_{m, H}$ to be $250 \%$ larger than the $\mathrm{CO}$ value and the $\mathrm{CO}_{2}$ mass transfer coefficient $k_{m, D}$ to be equal to the $\mathrm{CO}$ value. As expected, the primary value of high mass transfer coefficients was predicted to increase dissolved $\mathrm{CO}$ and $\mathrm{H}_{2}$ concentrations, with $\mathrm{CO}$ much more strongly affected (Fig. 5). Below our nominal value $k_{m, C}=80 \mathrm{~h}^{-1}$,
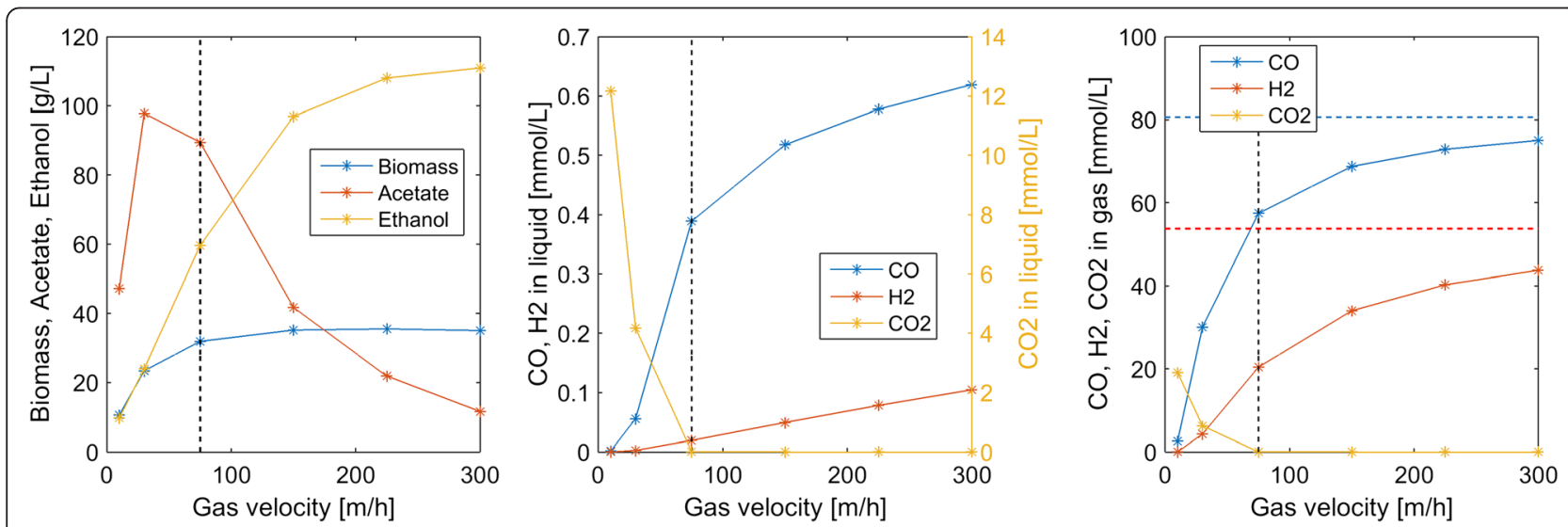

Fig. 4 Effect of the superficial gas velocity on steady-state concentrations in the exiting liquid and gas streams. The vertical dashed lines indicate the nominal superficial gas velocity used in the other simulations. The horizontal dashed lines indicate the inlet gas concentrations of $\mathrm{CO}$ and $\mathrm{H}_{2}$ 

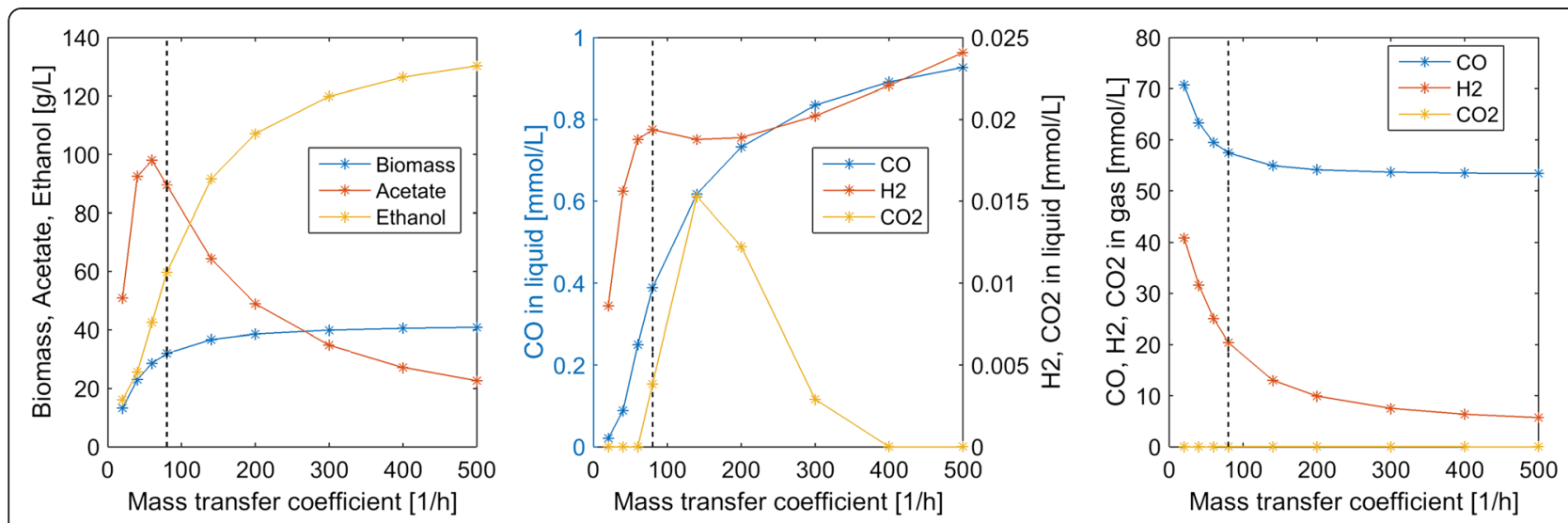

Fig. 5 Effect of the CO gas-liquid mass transfer coefficient $k_{m, c}$ on steady-state concentrations in the exiting liquid and gas streams. The $\mathrm{H}_{2}$ and $\mathrm{CO}_{2}$ mass transfer coefficients were set to be $2.5 k_{m, c}$ and $k_{m, c}$ respectively. The dashed lines indicate the nominal $k_{m, c}$ value used in the other simulations

acetate was the primary byproduct and no $\mathrm{CO}_{2}$ was synthesized. Above this nominal value, the acetate titer decreased rapidly and the ethanol titer increased rapidly such that the ethanol/acetate ratio was 5.75 at $k_{m, C}=500 \mathrm{~h}^{-1}$. Such high mass transfer coefficients can be achieved in bubble column reactors through the use of syngas microsparging and/or internal packing to increase gas-liquid contact [9]. Enhanced gas-liquid mass transfer also improved syngas consumption, with the $\mathrm{CO}$ and $\mathrm{H}_{2}$ conversions increased to 34 and $89 \%$, respectively, at $k_{m, C}=500 \mathrm{~h}^{-1}$.

Most column operating conditions investigated in this study were predicted to produce low syngas conversions due to limited gas-liquid mass transfer and cellular uptake rates. For example, our nominal conditions resulted in $62 \% \mathrm{H}_{2}$ conversion and $29 \% \mathrm{CO}$ conversion. One method for increasing these conversions is partial recycle of unconsumed gas exiting the top of the column (Fig. 1). We explored the effects of gas recycle by allowing a fraction $\alpha$ of the gas exiting the column to be recycled and mixed with the fresh syngas feed. While syngas conversion was predicted to be improved as expected, gas recycling had the undesirable effect of substantially reducing the ethanol titer and the ethanol/ acetate ratio (Fig. 6). This behavior seemed to be caused by decreasing dissolved $\mathrm{H}_{2}$ concentrations as the recycle ratio was increased.

\section{Impact of gas uptake parameters on bubble column performance}

The model was used to predict the effects of important gas uptake parameters on bubble column performance, as
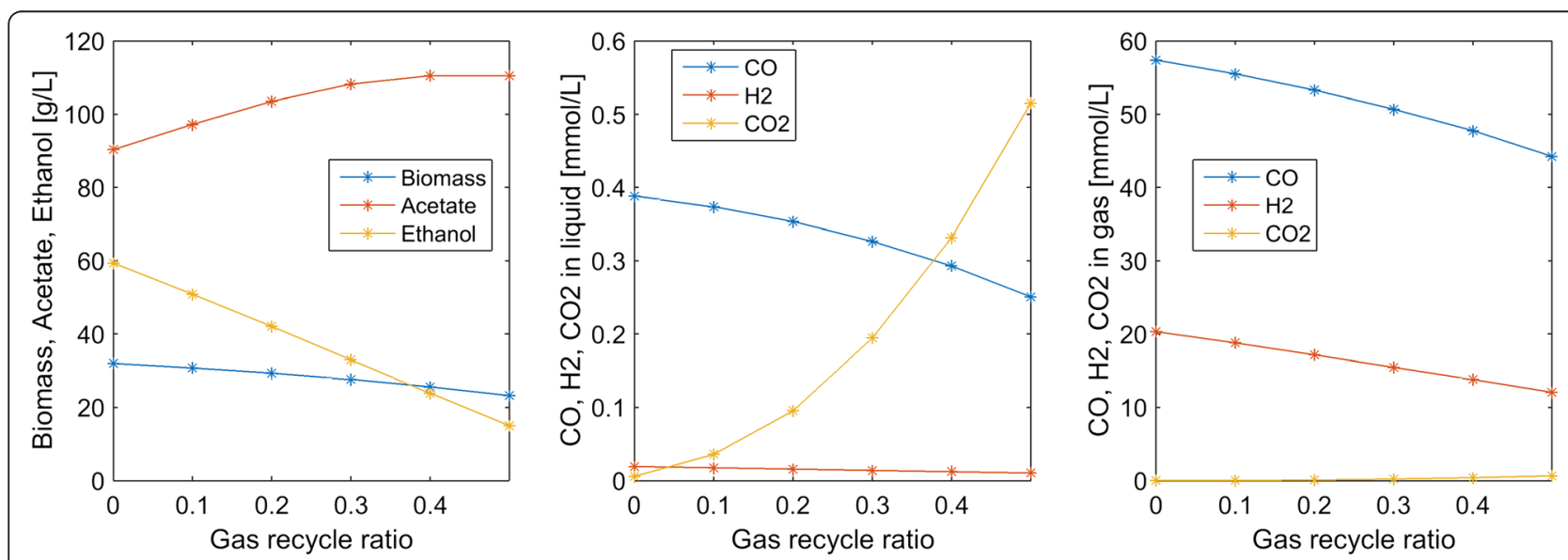

Fig. 6 Effect of the gas recycle ratio on steady-state concentrations in the exiting liquid and gas streams. No gas recycle was used in the other simulations 
measured by steady-state concentrations at the column exit as before. Because our nominal $\mathrm{CO}$ and $\mathrm{H}_{2}$ maximum uptake rate values had substantial uncertainty, we varied these maximum rates to investigate their impact. Both uptake rate parameters were predicted to have substantial effects on biomass production, with small rates insufficient to meet the ATP maintenance requirements of the cell and generating no growth (Fig. 7). The maximum rate parameters also affected both the amount and distribution of metabolic byproducts. For a $\mathrm{H}_{2}$ maximum uptake rate $v_{\max },_{H}=10 \mathrm{mmol} / \mathrm{gDW} / \mathrm{h}$, the model predicted that no ethanol would be synthesized regardless of the $\mathrm{CO}$ uptake rate. In this case, increasing amounts of acetate and $\mathrm{CO}_{2}$ were produced as the $\mathrm{CO}$ maximum uptake rate $v_{\max }, \mathrm{C}$ was increased. For larger $\mathrm{H}_{2}$ maximum uptake rates, increasing amounts of ethanol were synthesized up to $v_{\max }, C_{C}=25 \mathrm{mmol} / \mathrm{gDW} / \mathrm{h}$, at which point the ethanol titer began to drop while the acetate titer continued to increase. We also varied the saturation constants in the $\mathrm{CO}$ and $\mathrm{H}_{2}$ uptake rate expressions (Eq. 2) to examine their impacts. The main effect of increasing the $\mathrm{CO}$ saturation constant was to decrease the acetate titer and increase the ethanol titer by establishing more favorable ratios of the two gas uptake rates (results not shown). Decreasing the $\mathrm{H}_{2}$ saturation constant had the same effect.

Previous experimental studies $[8,13]$ have suggested that high dissolved $\mathrm{CO}$ levels can inhibit the uptake of
$\mathrm{CO}$ and/or $\mathrm{H}_{2}$. To explore the impact of such inhibitory effects, we modified the uptake rate expressions as follows:

$$
\begin{aligned}
v_{C} & =\frac{v_{\max , C} C}{K_{m, C}+C+C^{2} / K_{I, C}} \frac{1}{1+\frac{E+A}{K_{I}}} \\
v_{H} & =\frac{v_{\max , H} C}{K_{m, H}+H} \frac{1}{1+\frac{E+A}{K_{I}}} \frac{1}{1+\frac{C}{K_{I, H}}}
\end{aligned}
$$

where $K_{I},{ }_{C}$ and $K_{I, H}$ are parameters that account for $\mathrm{CO}$ inhibition of $\mathrm{CO}$ uptake and $\mathrm{H}_{2}$ uptake, respectively. Each parameter was varied independently to obtain three values that corresponded to no inhibition $\left(K_{I}, C_{C}=K_{I}, H_{H}=10^{6} \mathrm{~g} / \mathrm{L}\right)$, moderate inhibition, and strong inhibition. As expected, inhibition of either $\mathrm{CO}$ or $\mathrm{H}_{2}$ uptake was predicted to reduce steady-state biomass production throughout the column (Fig. 8). CO inhibition had the interesting effect of substantially reducing acetate synthesis but having very little impact on the exiting ethanol titer due to the establishment of more favorable intracellular $\mathrm{CO} / \mathrm{H}_{2}$ levels. At the highest level of inhibition, no acetate was produced and the ethanol titer was over $60 \mathrm{~g} / \mathrm{L}$. Conversely, CO inhibition of $\mathrm{H}_{2}$ uptake shifted the product distribution strongly towards acetate with no ethanol produced at the highest inhibition level.
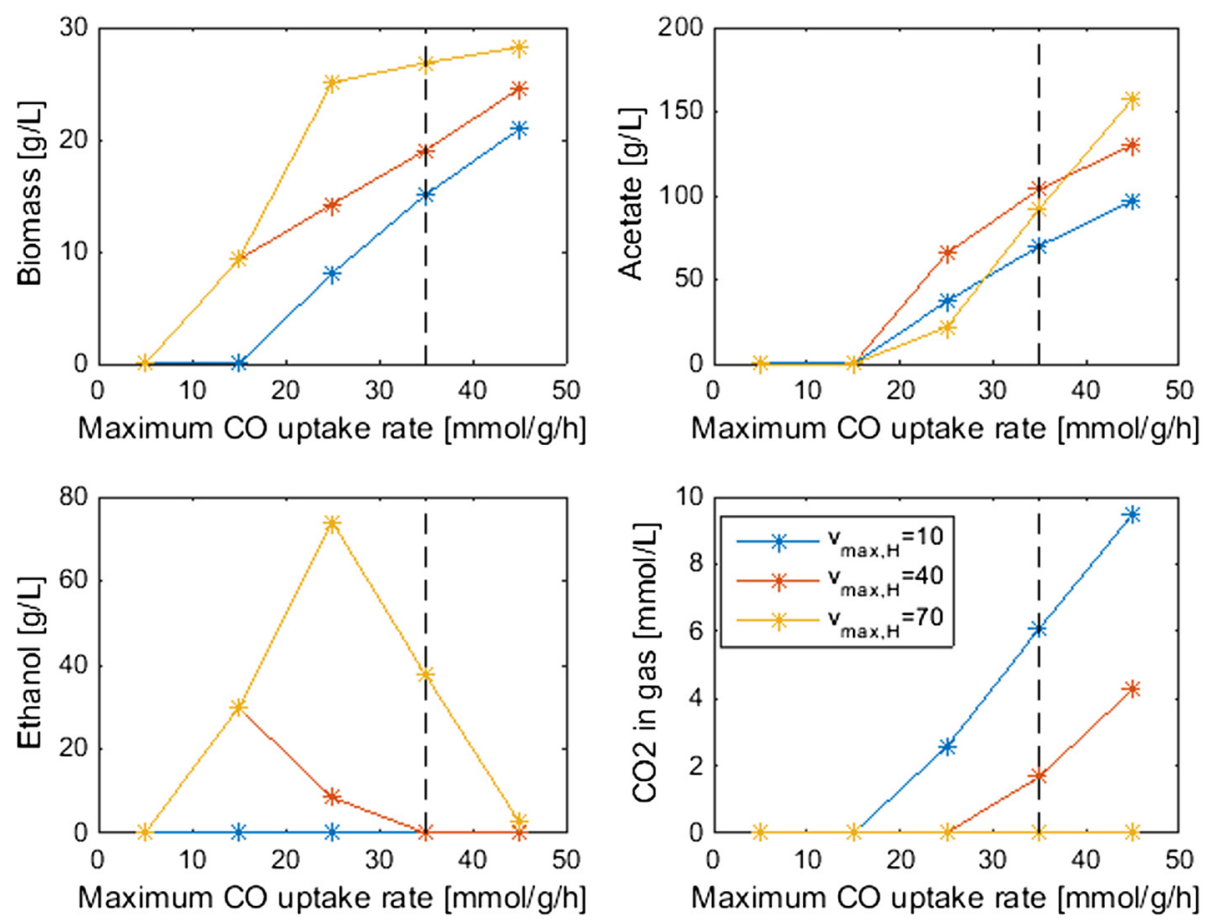

Fig. 7 Effect of the $\mathrm{CO}$ and $\mathrm{H}_{2}$ maximum uptake rate parameters on steady-state biomass and byproduct concentrations at the top column. The dashed lines indicate the nominal CO maximum uptake rate used in the other simulations. The nominal $\mathrm{H}_{2}$ maximum uptake rate was $v_{\max , H}=70 \mathrm{mmol} / \mathrm{gDW} / \mathrm{h}$ 

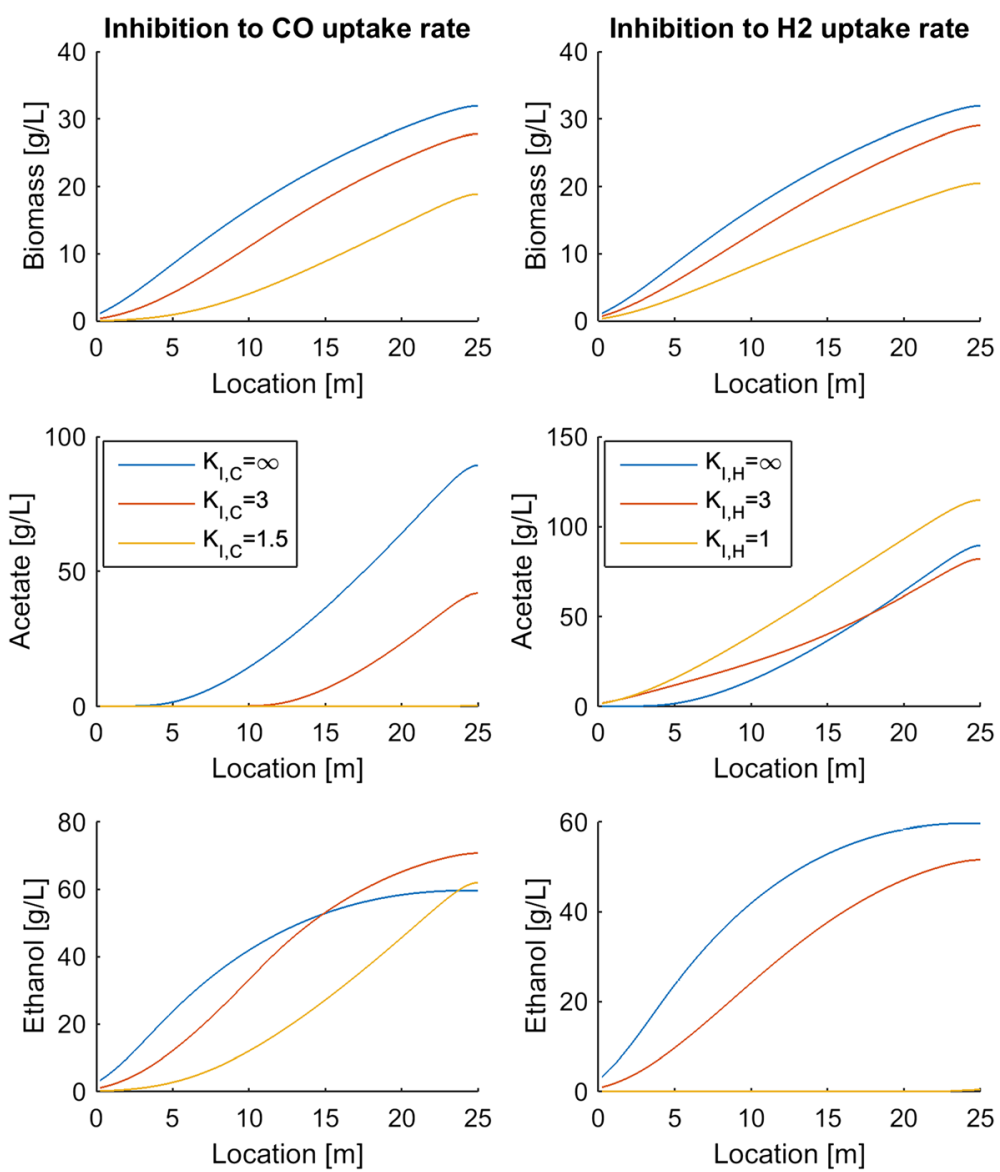

Fig. 8 Effect of $\mathrm{CO}$ inhibition of $\mathrm{CO}$ uptake (left) and $\mathrm{H}_{2}$ uptake (right) on steady-state biomass and byproduct production throughout the column. The nominal case corresponds to no inhibition $\left(K_{1, \mathrm{C}}=K_{1, H}=10^{6} \mathrm{~g} / \mathrm{L}\right)$

\section{Conclusions}

Bubble columns are the preferred reactor technology for industrial production of fuels and chemicals from synthesis gas. A number of experimental studies have been performed to investigate the effects of the microbial catalyst, the column design parameters, and the column operating conditions on syngas fermentation performance [9]. Because the effect of cellular and process parameters on column performance are complex, mathematical modeling provides a complementary tool to experimentation for understanding, predicting, and optimizing syngas fermentation reactors. We developed a spatiotemporal metabolic model for bubble column reactors by combining a genome-scale metabolic reconstruction of the syngas fermentating bacterium C. ljungdahlii with multiphase transport equations that govern convective and dispersive processes within the spatially varying column. To obtain a computationally tractable model, we performed spatial discretization to yield a large set of ordinary differential equations (ODEs) in time with embedded linear programs (LPs). Our initial attempts to solve the discretized model within MATLAB using a straightforward combination of built-in ODE solvers and the MOSEK LP solver proved unsuccessful. We found the recently developed MATLAB based code DFBAlab [26] to be a critical enabling tool, without which this study would not have been possible. Model translation into the DFBAlab format required minimal work.

Column startup was dynamically simulated with different process parameters to generate steady-state column profiles for analysis of parameter trends. Because the liquid product stream was removed from the top of the column, we focused our analysis on liquid and gas phase concentrations at this point. Our analysis was limited to syngas feed streams containing only $\mathrm{CO}$ and $\mathrm{H}_{2}$. We predicted the following trends that could guide column design and operation for maximization of ethanol production:

- A maximum ethanol titer of $120 \mathrm{~g} / \mathrm{L}$ and no acetate production were achieved at a $\mathrm{CO}$ mole fraction of 0.45 (Fig. 3). The ethanol concentration decreased rapidly, $\mathrm{CO}_{2}$ synthesis occurred and acetate quickly became the dominant byproduct at higher $\mathrm{CO}$ mole 
fractions, suggesting that $\mathrm{H}_{2}$ augmentation of CO-rich syngas feeds may be beneficial.

- High superficial gas velocities enhanced the ethanol titer and ethanol/acetate split at the expense of low $\mathrm{CO}$ and $\mathrm{H}_{2}$ conversions (Fig. 4), indicating the possible benefit of recycling unconsumed gas to achieve higher conversions.

- Partial recycling of unconsumed gas showed the potential to substantially improve $\mathrm{CO}$ and $\mathrm{H}_{2}$ conversions at the expense of increased gas compression costs (Fig. 6). Because recycling had the negative effect of reducing the ethanol titer and the ethanol/acetate ratio due to depleted $\mathrm{H}_{2}$ levels, $\mathrm{H}_{2}$ augmentation may be necessary to achieve acceptable process economics.

- Enhanced ethanol titer and ethanol/acetate split were achieved with increasing liquid velocity up to a critical value at which the column was washed out (results not shown). The development of reactor monitoring and control strategies would be necessary to stably operate near this critical value.

- Increasing reactor length enhanced both the ethanol titer and the ethanol/acetate split (results not shown). Because taller reactors required more syngas feed compression, an economic analysis would be needed to determine the optimal length.

- Efficient gas-liquid mass transfer was found to be critical to achieve high ethanol production and high conversions (Fig. 5). A CO mass transfer coefficient of $500 \mathrm{~h}^{-1}$ was predicted to produce an ethanol titer of $130 \mathrm{~g} / \mathrm{L}$, an ethanol/acetate ratio of 6 , and $\mathrm{CO}$ and $\mathrm{H}_{2}$ conversions of 34 and $89 \%$, respectively, for a syngas feed containing $60 \% \mathrm{CO}$. These results demonstrate the need for continued development of advanced bubble column designs that achieve very high gas-liquid mass transfer rates.

- The bubble column model also was used to investigate the effect of $\mathrm{CO}$ and $\mathrm{H}_{2}$ uptake parameters on reactor performance. The following trends were observed that could guide the engineering of bacterial syngas uptake kinetics for ethanol overproduction:

- Enhanced $\mathrm{H}_{2}$ uptake rates achieved either by increasing the maximum uptake rate or by reducing the uptake saturation constant substantially increased the ethanol titer and the ethanol/acetate ratio (Fig. 7). Consequently, C. ljungdahlii engineering efforts should focus on increasing $\mathrm{H}_{2}$ uptake rates.

- Ethanol and/or acetate inhibition of growth modeled as inhibition of the $\mathrm{CO}$ and $\mathrm{H}_{2}$ uptakes reduced biomass production but increased the ethanol titer and the ethanol/acetate ratio (results not shown).
Therefore, cellular engineering efforts aimed at reducing byproduct inhibition may have limited effectiveness.

- Inhibition of CO uptake at high CO levels reduced biomass production but had almost no effect on the ethanol titer while reducing acetate synthesis (Fig. 8). Conversely, $\mathrm{CO}$ inhibition of $\mathrm{H}_{2}$ uptake reduced growth and shifted the product distribution strongly towards acetate. Consequently, C. ljungdahlii engineering efforts should focus on alleviating $\mathrm{CO}$ inhibition of $\mathrm{H}_{2}$ uptake.

Future work on syngas bubble column modeling could include the incorporation of more realistic column hydrodynamics [29] to improve model fidelity.

\section{Methods}

\section{Model formulation}

The bubble column model was formulated by combining a genome-scale metabolic reconstruction of $C$. ljungdahlii with uptake kinetics for dissolved gases and reactionconvection-dispersion type equations for gaseous and dissolved substrates and synthesized metabolic byproducts. The C. ljungdahlii iHN637 reconstruction accounts for 637 genes, 698 metabolites, 690 intracellular reactions, and 95 exchange reactions that capture the primary metabolic pathways involved in synthesis gas fermentation [21]. The model has been shown to produce growth on several known substrates including $\mathrm{CO}$ and $\mathrm{CO}_{2} / \mathrm{H}_{2}$ mixtures as well as to provide good agreement with experimentally determined growth and acetate production rates on fructose. Our preliminary flux balance calculations with the typical maximum growth objective showed that the primary metabolic byproducts for growth on $\mathrm{CO} / \mathrm{H}_{2}$ mixtures were ethanol, acetate, and $\mathrm{CO}_{2}$. We assumed that the extracellular $\mathrm{pH}$ was maintained constant throughout the reactor such that the intracellular $\mathrm{pH}$ could be assumed constant at the value used for charge balancing of the metabolic reconstruction [21].

Uptake kinetics were specified for the dissolved gaseous substrates $\mathrm{CO}$ and $\mathrm{H}_{2}$ as well as for the dissolved gaseous byproduct $\mathrm{CO}_{2}$ that could be reassimilated. Uptake kinetics were assumed to follow inhibited Monod expressions of the form,

$$
v_{i}=\frac{v_{\max , i} S_{i}}{K_{m, i}+S_{i}} \frac{1}{1+\frac{E+A}{K_{I}}}
$$

where $v_{i}$ is the uptake rate $(\mathrm{mmol} / \mathrm{gDW} / \mathrm{h})$ of the $i$-th substrate, $S_{i}$ is the dissolved concentration $(\mathrm{mmol} / \mathrm{L})$ of the $i$-th gaseous substrate, $v_{\max }, i$ is the maximum uptake rate, $K_{m}, i$ is the saturation constant, and $K_{I}$ is an inhibition constant. A combined term involving both the concentrations of ethanol $(E)$ and acetate $(A)$ was used 
to account for the known inhibitory effects of these two products on C. ljungdahlii growth [22, 30]. To reduce the number of model parameters, the two products were assumed to induce equal inhibition of all substrate uptake rates such that only a single $K_{I}$ value was needed to model inhibition of growth due to high ethanol and/or acetate concentrations. Equation (2) was used to establish bounds on the possible uptake rates with the actual uptake rates being determined by the solution of the intracellular flux balance problem. Both $v_{\max i}$ and $K_{m, i}$ were important parameters due to the large dissolved gas concentration gradients in the bubble column reactor (see Results).

Despite synthesis gas fermentation being an active research area, we found a dearth of literature for determining the parameter values needed to calculate uptake rates for the three possible substrates $\left(\mathrm{CO}, \mathrm{H}_{2}, \mathrm{CO}_{2}\right)$. Parameter values for the $\mathrm{CO}$ maximum uptake rate and saturation constant were obtained from a recent experimental study [13]. Based on our own limited experimental data (unpublished), we assumed that the $\mathrm{H}_{2}$ maximum uptake rate was double the $\mathrm{CO}$ value. Because data was lacking for determination of the remaining parameters, the $\mathrm{CO}_{2}$ maximum uptake rate and the $\mathrm{H}_{2}$ and $\mathrm{CO}_{2}$ saturation constants were taken to be equal to the corresponding $\mathrm{CO}$ values. The value of the inhibition constant was chosen based on our previous modeling efforts involving uptake inhibition by ethanol and other toxic byproducts (Hanly and Henson 2014). Due to the large uncertainties associated with these parameter values (Table 1), we explored the sensitivity of our model predictions to the dissolved gas uptake kinetics.

The genome-scale reconstruction of intracellular metabolism and the substrate uptake kinetics were combined with reaction-convection-dispersion type equations for the bubble column transport processes. Because our focus was describing spatially varying cellular metabolism rather than detailed modeling of the potentially complex column hydrodynamics [29], we assumed ideal plug flow for the vapor phase and plug flow plus axial dispersion for the liquid phase. These assumptions represent reasonable simplifications given the gas superficial velocities within the bubbly flow regime $(<5 \mathrm{~cm} / \mathrm{s} ;[29])$ and the very small liquid velocities $(<0.02 \mathrm{~cm} / \mathrm{s})$ used in our simulations. Convection and dispersion were assumed to occur only in

Table 1 Nominal dissolved gas uptake parameters

\begin{tabular}{llll}
\hline Substrate & $V_{\max }(\mathrm{mmol} / \mathrm{gDW} / \mathrm{h})$ & $K_{m}(\mathrm{mmol} / \mathrm{L})$ & Source \\
\hline $\mathrm{CO}$ & 35 & 0.02 & {$[13]$} \\
$\mathrm{H}_{2}$ & 70 & 0.02 & Specified \\
$\mathrm{CO}_{2}$ & 35 & 0.02 & Specified \\
Substrate & $K_{/}(\mathrm{g} / \mathrm{L})$ & & Source \\
All & 10 & & Specified \\
\hline
\end{tabular}

the axial direction of the bubble column reactor such that spatial variations could be captured with a single variable $z$.

The mass balance of C. ljungdahlii biomass had the form,

$$
\begin{aligned}
& \frac{\partial X(z, t)}{\partial t}=\mu X-\frac{u_{L}}{\varepsilon_{L}} \frac{\partial X}{\partial z}+D_{A} \frac{\partial^{2} X}{\partial z^{2}} \\
& u_{L} X(0, t)-\varepsilon_{L} D_{A} \frac{\partial X(0, t)}{\partial z}=0 \quad \frac{\partial X(L, t)}{\partial z}=0 \quad X(z, 0)=X_{0}
\end{aligned}
$$

where $X$ is the biomass concentration $(\mathrm{g} / \mathrm{L}), \mu$ is cellular growth rates $\left(\mathrm{h}^{-1}\right)$ obtained from the flux balance calculation, $u_{L}$ is the liquid phase velocity, $\varepsilon_{\mathrm{L}}$ is the liquid phase volume fraction, and $D_{A}$ is the axial dispersion coefficient of the liquid phase. A typical Danckwerts boundary condition was imposed at the reactor entrance $(z=0)$, while a zero slope boundary condition was applied at the reactor exit $(z=L)$. A uniform biomass concentration profile within the reactor was used as the initial condition.

Mass balances of the dissolved gaseous substrates had the form,

$$
\begin{aligned}
& \frac{\partial C_{L}(z, t)}{\partial t}=v_{C} X+\frac{k_{m, C}}{\varepsilon_{L}}\left(C^{*}-C_{L}\right)-\frac{u_{L}}{\varepsilon_{L}} \frac{\partial C_{L}}{\partial z}+D_{A} \frac{\partial^{2} C_{L}}{\partial z^{2}} \\
& u_{L} C_{L}(0, t)-\varepsilon_{L} D_{A} \frac{\partial C_{L}(0, t)}{\partial z}=0 \quad \frac{\partial C_{L}(L, t)}{\partial z}=0 \quad C_{L}(z, 0)=C_{L 0} \\
& \frac{\partial H_{L}(z, t)}{\partial t}=v_{H} X+\frac{k_{m, H}}{\varepsilon_{L}}\left(H^{*}-H_{L}\right)-\frac{u_{L}}{\varepsilon_{L}} \frac{\partial H_{L}}{\partial z}+D_{A} \frac{\partial^{2} H_{L}}{\partial z^{2}} \\
& u_{L} H_{L}(0, t)-\varepsilon_{L} D_{A} \frac{\partial H_{L}(0, t)}{\partial z}=0 \quad \frac{\partial H_{L}(L, t)}{\partial z}=0 \quad H_{L}(z, 0)=H_{L 0}
\end{aligned}
$$

where $C_{L}$ and $H_{L}$ are the liquid phase $\mathrm{CO}$ and $\mathrm{H}_{2}$ concentrations $(\mathrm{mmol} / \mathrm{L}), v_{C}$ and $v_{H}$ are the $\mathrm{CO}$ and $\mathrm{H}_{2}$ uptake rates $(\mathrm{mmol} / \mathrm{gDW} / \mathrm{h})$ obtained from the flux balance calculation, $\mathbf{k}_{m, C}$ and $\mathbf{k}_{m, H}$ are the corresponding gas-liquid mass transfer coefficients, and $\mathrm{C}^{*}$ and $\mathrm{H}^{*}$ are the saturated liquid concentrations $(\mathrm{mmol} / \mathrm{L}) \mathrm{cal}-$ culated from the corresponding gas phase concentrations using Henry's law at the specified temperature and pressure. Constant gas-liquid mass transfer coefficients were used for simplicity despite their known dependence on various factors including gas bubble size [31], which was not modeled in this study. The Danckwerts boundary conditions imposed at the reactor entrance assumed the form shown since dissolved gases were not fed to the reactor, while zero slope boundary conditions were applied at the reactor exit. Uniform concentration profiles calculated from the initial gas phase concentrations using Henry's law were imposed as initial conditions, which was consistent with the liquid phase being saturated with the feed gases prior to inoculation. 
Mass balances of the two substrates in the gas phase had the form,

$$
\begin{aligned}
& \frac{\partial C_{G}(z, t)}{\partial t}=-\frac{k_{m, C}}{\varepsilon_{G}}\left(C^{*}-C_{L}\right)-\frac{u_{G}}{\varepsilon_{G}} \frac{\partial C_{G}}{\partial z} \quad C_{G}(0, t)=C_{G F} C_{G}(z, 0)=C_{G 0} \\
& \frac{\partial H_{G}(z, t)}{\partial t}=-\frac{k_{m, H}}{\varepsilon_{G}}\left(H^{*}-H_{L}\right)-\frac{u_{G}}{\varepsilon_{G}} \frac{\partial H_{G}}{\partial z} \quad H_{G}(0, t)=H_{G F} H_{G}(z, 0)=H_{G 0}
\end{aligned}
$$

where $C_{G}$ and $H_{G}$ are the gas phase $\mathrm{CO}$ and $\mathrm{H}_{2}$ concentrations $(\mathrm{mmol} / \mathrm{L}), \varepsilon_{\mathrm{G}}=1-\varepsilon_{\mathrm{L}}$ is the gas phase volume fraction, and $u_{G}$ is the superficial gas velocity. The gas concentrations at the reactor entrance $C_{G F}$ and $H_{G F}$ were calculated from the partial pressures of the feed gas using the ideal gas law. Uniform initial conditions were specified by setting $C_{G O}=C_{G F}$ and $H_{G O}=H_{G F}$, which again was consistent with the liquid phase being saturated with the feed gases prior to inoculation.

Mass balances on the two major metabolic byproducts ethanol and acetate had the form,

$$
\begin{aligned}
& \frac{\partial E_{L}(z, t)}{\partial t}=M_{E} v_{E} X-\frac{u_{L}}{\varepsilon_{L}} \frac{\partial E_{L}}{\partial z}+D_{A} \frac{\partial^{2} E_{L}}{\partial z^{2}} \\
& u_{L} E_{L}(0, t)-\varepsilon_{L} D_{A} \frac{\partial E_{L}(0, t)}{\partial z}=0 \quad \frac{\partial E_{L}(L, t)}{\partial z}=0 \quad E_{L}(z, 0)=E_{L 0} \\
& \frac{\partial A_{L}(z, t)}{\partial t}=M_{A} v_{A} X-\frac{u_{L}}{\varepsilon_{L}} \frac{\partial A_{L}}{\partial z}+D_{A} \frac{\partial^{2} A_{L}}{\partial z^{2}} \\
& u_{L} A_{L}(0, t)-\varepsilon_{L} D_{A} \frac{\partial A_{L}(0, t)}{\partial z}=0 \quad \frac{\partial A_{L}(L, t)}{\partial z}=0 \quad A_{L}(z, 0)=A_{L 0}
\end{aligned}
$$

where $E_{L}$ and $A_{L}$ are the concentrations of liquid phase ethanol $(\mathrm{g} / \mathrm{L})$ and acetate $(\mathrm{g} / \mathrm{L}), v_{E}$ and $v_{A}$ are the corresponding fluxes $(\mathrm{mmol} / \mathrm{L})$ calculated from the flux balance model, and $M_{E}$ and $M_{A}$ are the corresponding molecular weight $(\mathrm{g} / \mathrm{mmol})$. Gas phase balances on ethanol and acetate were omitted under the assumption of low volatility at column conditions. Danckwerts boundary conditions were imposed at the reactor entrance and zero slope boundary conditions were applied at the reactor exit as before. Uniform ethanol and acetate concentration profiles were used as initial conditions.

Mass balances on liquid and gas phase carbon dioxide had the form,

$$
\begin{gathered}
\frac{\partial D_{L}(z, t)}{\partial t}=v_{D} X+\frac{k_{m, D}}{\varepsilon_{L}}\left(D^{*}-D_{L}\right)-\frac{u_{L}}{\varepsilon_{L}} \frac{\partial D_{L}}{\partial z}+D_{A} \frac{\partial^{2} D_{L}}{\partial z^{2}} \\
u_{L} D_{L}(0, t)-\varepsilon_{L} D_{A} \frac{\partial D_{L}(0, t)}{\partial z}=0 \quad \frac{\partial D_{L}(L, t)}{\partial z}=0 \quad D_{L}(z, 0)=D_{L 0} \\
\frac{\partial D_{G}(z, t)}{\partial t}=-\frac{k_{m, D}}{\varepsilon_{G}}\left(D^{*}-D_{L}\right)-\frac{u_{G}}{\varepsilon_{G}} \frac{\partial D_{L}}{\partial z} \\
D_{G}(0, t)=D_{G F} \quad D_{G}(z, 0)=D_{G 0}
\end{gathered}
$$

where $D_{L}$ and $D_{G}$ are the concentrations of liquid phase $\mathrm{CO}_{2}(\mathrm{mmol} / \mathrm{L})$ and gas phase $\mathrm{CO}_{2}(\mathrm{mmol} / \mathrm{L}), v_{D}$ is the $\mathrm{CO}_{2}$ flux $(\mathrm{mmol} / \mathrm{L})$ calculated from the flux balance model, $\mathrm{k}_{m, D}$ is the $\mathrm{CO}_{2}$ gas-liquid mass transfer coefficient, and $\mathrm{D}^{*}$ is the saturated liquid $\mathrm{CO}_{2}$ concentration $(\mathrm{mmol} / \mathrm{L})$ calculated from the corresponding gas phase concentration using Henry's law. For liquid phase $\mathrm{CO}_{2}$, Danckwerts and zero slope boundary conditions were applied at the reactor entrance and exit as before. The $\mathrm{CO}_{2}$ concentration at the reactor entrance $D_{G F}$ was calculated from the $\mathrm{CO}_{2}$ partial pressure of the feed gas using the ideal gas law. This formulation allowed $\mathrm{CO}_{2}$ to be a feed component and/or a metabolic byproduct. A uniform liquid phase $\mathrm{CO}_{2}$ concentration profile calculated from the initial $\mathrm{CO}_{2}$ gas phase concentration using Henry's law was imposed as an initial condition. A uniform initial condition for gas phase $\mathrm{CO}_{2}$ was specified by setting $D_{G O}=D_{G F}$.

The reactor was assumed to be isothermal, while the pressure profile was calculated from the liquid head as,

$$
P(z)=P_{L}+\rho_{L} g(L-z)
$$

where $L$ is the length of the column, $\rho$ is the liquid phase density assumed to be equal to the density of water, and $P_{L}$ is the pressure $(\mathrm{Pa})$ at the top of the column, which was assumed to be atmospheric pressure. Accordingly, gaseous substrates were modeled to dissolve more readily in the lower portion of the column. Calculation of gas and liquid volume fractions in bubble column reactors is notoriously difficult, as the volume fractions are known to depend on a number of operating parameters [29]. The effect of the gas flow rate is known to be particularly important. Therefore, we fit gas flow rate versus gas volume fraction data [32] to a simple model [33] to derive the following relationship:

$$
\varepsilon_{g}=\frac{\varepsilon_{G, \max } u_{G}}{K_{G}+u_{G}}
$$

where $\varepsilon_{G}$, max is the maximum achievable gas volume fraction and $K_{G}$ is a type of saturation constant.

Parameter values for the bubble column reactor model were obtained from the literature to the extent possible (Tables 1 and 2). The reactor length and cross-sectional area were chosen to represent an industrial scale reactor with volume of 125,000 $\mathrm{l}$ and a typical length-todiameter ratio of 10 [29]. The liquid and superficial gas velocities were chosen to achieve a liquid residence time of $100 \mathrm{~h}$ to maintain the gas flow in the homogeneous, bubbly regime $(<5 \mathrm{~cm} / \mathrm{s})$ where dispersion effects would be small and to achieve a high gas-to-liquid velocity ratio of 300 [29]. A small value of the liquid phase dispersion coefficient was specified to improve numerical stability of the model (see "Model solution") while ensuring that the liquid flow would be convection controlled. A feed stream with a 1.5:1 $\mathrm{CO}: \mathrm{H}_{2}$ ratio and devoid of $\mathrm{CO}_{2}$ was used to model a $\mathrm{CO}$-rich syngas 
Table 2 Nominal parameter values for the synthesis gas bubble column reactor

\begin{tabular}{|c|c|c|c|}
\hline Parameter & Symbol & Value & Source \\
\hline Reactor length & L & $25 \mathrm{~m}$ & Specified \\
\hline Reactor cross-sectional area & $A$ & $5 \mathrm{~m}^{2}$ & Specified \\
\hline Superficial gas velocity & $u_{G}$ & $75 \mathrm{~m} / \mathrm{h}$ & Specified \\
\hline Liquid phase velocity & $u_{L}$ & $0.25 \mathrm{~m} / \mathrm{h}$ & Specified \\
\hline $\begin{array}{l}\text { Liquid phase dispersion } \\
\text { coefficient }\end{array}$ & $D_{A}$ & $0.25 \mathrm{~m}^{2} / \mathrm{h}$ & Specified \\
\hline Temperature & $T$ & $37^{\circ} \mathrm{C}$ & [3] \\
\hline Pressure at top of column & $P_{L}$ & $1.013 \times 10^{5} \mathrm{~Pa}$ & Specified \\
\hline CO mole fraction in feed gas & $x_{C}$ & 0.6 & Specified \\
\hline $\mathrm{H}_{2}$ mole fraction in feed gas & $x_{H}$ & 0.4 & Specified \\
\hline $\mathrm{CO}_{2}$ mole fraction in feed gas & $x_{D}$ & 0 & Specified \\
\hline CO Henry's law constant & $H_{C}$ & $8 \times 10^{-4} \mathrm{~mol} / \mathrm{L} / \mathrm{atm}$ & {$[35]$} \\
\hline $\mathrm{H}_{2}$ Henry's law constant & $H_{H}$ & $6.6 \times 10^{-4} \mathrm{~mol} / \mathrm{L} / \mathrm{atm}$ & {$[35]$} \\
\hline $\mathrm{CO}_{2}$ Henry's law constant & $H_{D}$ & $2.5 \times 10^{-2} \mathrm{~mol} / \mathrm{L} / \mathrm{atm}$ & {$[35]$} \\
\hline $\begin{array}{l}\text { CO gas-liquid mass transfer } \\
\text { coefficient }\end{array}$ & $k_{m, c}$ & $80 h^{-1}$ & [9] \\
\hline $\begin{array}{l}\mathrm{H}_{2} \text { gas-liquid mass transfer } \\
\text { coefficient }\end{array}$ & $k_{m, H}$ & $200 h^{-1}$ & {$[34]$} \\
\hline $\begin{array}{l}\mathrm{CO}_{2} \text { gas-liquid mass transfer } \\
\text { coefficient }\end{array}$ & $k_{m, D}$ & $80 h^{-1}$ & Specified \\
\hline Maximum gas volume fraction & $\varepsilon_{G, \max }$ & 0.53 & Fit to data \\
\hline $\begin{array}{l}\text { Gas volume fraction saturation } \\
\text { constant }\end{array}$ & $K_{G}$ & $540 \mathrm{~m} / \mathrm{h}$ & Fit to data \\
\hline Gas volume fraction & $\varepsilon_{G}$ & 0.0646 & Calculated \\
\hline $\begin{array}{l}\text { CO concentration at reactor } \\
\text { entrance }\end{array}$ & $C_{G F}$ & $80.64 \mathrm{mmol} / \mathrm{L}$ & Calculated \\
\hline $\begin{array}{l}\mathrm{H}_{2} \text { concentration at reactor } \\
\text { entrance }\end{array}$ & $H_{G F}$ & $53.76 \mathrm{mmol} / \mathrm{L}$ & Calculated \\
\hline $\begin{array}{l}\mathrm{CO}_{2} \text { concentration at reactor } \\
\text { entrance }\end{array}$ & $D_{G F}$ & $0 \mathrm{mmol} / \mathrm{L}$ & Calculated \\
\hline Initial biomass concentration & $x_{0}$ & $0.1 \mathrm{~g} / \mathrm{L}$ & Specified \\
\hline $\begin{array}{l}\text { Initial gas phase CO } \\
\text { concentration }\end{array}$ & $C_{G O}$ & $80.64 \mathrm{mmol} / \mathrm{L}$ & Calculated \\
\hline $\begin{array}{l}\text { Initial gas phase } \mathrm{H}_{2} \\
\text { concentration }\end{array}$ & $H_{G O}$ & $53.76 \mathrm{mmol} / \mathrm{L}$ & Calculated \\
\hline $\begin{array}{l}\text { Initial gas phase } \mathrm{CO}_{2} \\
\text { concentration }\end{array}$ & $D_{G O}$ & $0 \mathrm{mmol} / \mathrm{L}$ & Calculated \\
\hline $\begin{array}{l}\text { Initial liquid phase CO } \\
\text { concentration }\end{array}$ & $C_{L O}$ & $1.642 \mathrm{mmol} / \mathrm{L}$ & Calculated \\
\hline $\begin{array}{l}\text { Initial liquid phase } \mathrm{H}_{2} \\
\text { concentration }\end{array}$ & $H_{\llcorner O}$ & $0.903 \mathrm{mmol} / \mathrm{L}$ & Calculated \\
\hline $\begin{array}{l}\text { Initial liquid phase } \mathrm{CO}_{2} \\
\text { concentration }\end{array}$ & $D_{L O}$ & $0 \mathrm{mmol} / \mathrm{L}$ & Calculated \\
\hline $\begin{array}{l}\text { Initial liquid phase ethanol } \\
\text { concentration }\end{array}$ & $E_{L O}$ & $0 \mathrm{mmol} / \mathrm{L}$ & Specified \\
\hline $\begin{array}{l}\text { Initial liquid phase acetate } \\
\text { concentration }\end{array}$ & $A_{L O}$ & $0 \mathrm{mmol} / \mathrm{L}$ & Specified \\
\hline
\end{tabular}

mixture [9]. A very wide range of $\mathrm{CO}$ gas-liquid mass transfer coefficients that differ according to the reactor configuration, gas sparging method, and agitation rate have been reported [9]. We conservatively selected the $\mathrm{CO}$ mass transfer coefficient to be consistent with a bubble column without microsparging and internal packing. Based on the limited literature available [34], we chose the $\mathrm{H}_{2}$ gas-liquid mass transfer coefficient to be 250 \% larger than the $\mathrm{CO}$ value. The $\mathrm{CO}_{2}$ mass transfer coefficient was specified to be equal to the $\mathrm{CO}$ value due to lack of data. Due to the large variability associated with these parameter values, we explored the sensitivity of our model predictions to the mass transfer coefficients. The initial conditions were chosen to mimic a newly inoculated reactor with saturated liquid compositions and no spatial gradients.

\section{Model solution}

The bubble column reactor model is consisted of a set of PDEs for multiphase transport processes with embedded linear programs that described intracellular metabolism. We spatially discretized the PDE model using third-order finite differences for the convection terms and second-order central differences for the diffusion terms. The resulting ODE system with embedded LPs was solved with DFBAlab [26], a MATLAB code specifically designed for large-scale dynamic FBA simulations, combined with the LP solver Gurobi and the stiff ODE solver ode15s. DFBAlab requires the specification of lexicographic optimization objectives to avoid the common problem of non-unique exchange fluxes that render the ODE system impossible to integrate. The objectives were sequentially applied in the following order: (1) maximization of the growth rate, (2) maximization of the $\mathrm{CO}$ uptake rate, (3) maximization of the $\mathrm{H}_{2}$ uptake rate, (4) minimization of the $\mathrm{CO}_{2}$ synthesis rate, (5) minimization of the acetate synthesis rate, and (6) minimization of the ethanol synthesis rate. The ordering of these objectives had no effect on model predictions. We found that 100 spatial node points (900 ODEs, 600 LPs) provided a suitable compromise between solution accuracy and computation time. Additional details on the numerical solution procedure are available in the forthcoming publication.

\section{Abbreviations}

DFBAlab: Dynamic flux balance analysis laboratory; FBA: Flux balance analysis; LP: Linear program; ODE: Ordinary differential equation; PDE: Partial differential equation.

\section{Competing interests}

The authors declare that they have no competing interests.

\section{Authors' contributions}

$J \mathrm{C}$ and MAH conceived the study and developed the model. JC, JAG, KH, and PIB developed the model solution method. JC performed the simulations and analyzed the results. JC, JAG, $\mathrm{KH}$, and MAH prepared the manuscript. All authors read and approved the final manuscript. 


\section{Acknowledgements}

$J \mathrm{C}$ and MAH wish to acknowledge the financial support from the ReCommunity Recycling and assistance from the Harish Nagarajan (UCSD) with the C. ljungdahlii genome-scale metabolic reconstruction.

\section{Author details}

'Department of Chemical Engineering, University of Massachusetts, Amherst, MA 010003, USA. ${ }^{2}$ Process Systems Engineering Laboratory, Department of Chemical Engineering, Massachusetts Institute of Technology, Cambridge, MA 02139, USA.

Received: 22 March 2015 Accepted: 9 June 2015

Published online: 20 June 2015

\section{References}

1. Kirkels AF, Verbong GPJ. Biomass gasification: still promising? A 30-year global overview. Renew Sust Energ Rev. 2011;15(1):471-81.

2. McKendry P. Energy production from biomass (part 3): gasification technologies. Bioresour Technol. 2002;83(1):55-63.

3. Tanner RS, Miller LM, Yang D. Clostridium ljungdahlii sp. nov., an acetogenic species in clostridial rRNA homology group I. Int I Syst Bacteriol. 1993;43(2):232-6.

4. Tanner RS. Production of ethanol from synthesis gas. In: Wall J, Harwood C Demain A, editors. Bioenergy. Washington, DC: ASM Press; 2008. p. 147-51.

5. Sim JH, Kamaruddin AH, Long WS, Najafpour G. Clostridium aceticum-a potential organism in catalyzing carbon monoxide to acetic acid: application of response surface methodology. Enzyme Microb Technol. 2007:40(5):1234-43.

6. Genthner BRS, Bryant MP. Additional characteristics of one-carboncompound utilization by Eubacterium limosum and Acetobacterium woodii. Appl Environ Microbiol. 1987;53(3):471-6.

7. Liou JSC, Balkwill DL, Drake GR, Tanner RS. Clostridium carboxidivorans sp. nov., a solvent-producing clostridium isolated from an agricultural settling lagoon, and reclassification of the acetogen Clostridium scatologenes strain SL1 as Clostridium drakei sp. nov. Int I Syst Evol Microbiol. 2005;55:2085-91.

8. Daniell J, Kopke M, Simpson SD. Commercial biomass syngas fermentation. Energies. 2012:5(12):5372-417.

9. Munasinghe PC, Khanal SK. Biomass-derived syngas fermentation into biofuels: opportunities and challenges. Bioresour Technol. 2010;101(13):5013-22.

10. Abubackar HN, Veiga MC, Kennes C. Biological conversion of carbon monoxide: rich syngas or waste gases to bioethanol. Biofuel Bioprod Bior. 2011;5(1):93-114.

11. Riggs SS, Heindel TJ. Measuring carbon monoxide gas-liquid mass transfer in a stirred tank reactor for syngas fermentation. Biotechnol Prog. 2006;22(3):903-6.

12. Hurst KM, Lewis RS. Carbon monoxide partial pressure effects on the metabolic process of syngas fermentation. Biochem Eng J. 2010;48(2):159-65.

13. Mohammadi M, Mohamed AR, Najafpour GD, Younesi H, Uzir MH. Kinetic studies on fermentative production of biofuel from synthesis gas using Clostridium ljungdahlii. Sci World J. 2014;2014:910590.

14. Datar RP, Shenkman RM, Cateni BG, Huhnke RL, Lewis RS. Fermentation of biomass-generated producer gas to ethanol. Biotechnol Bioeng. 2004;86(5):587-94.

15. Henstra AM, Sipma J, Rinzema A, Stams AJM. Microbiology of synthesis gas fermentation for biofuel production. Curr Opin Biotechnol. 2007;18(3):200-6.

16. Papin JA, Price ND, Wiback SJ, Fell DA, Palsson BO. Metabolic pathways in the post-genome era. Trends Biochem Sci. 2003;28(5):250-8

17. Hanly TJ, Henson MA. Dynamic flux balance modeling of microbial co-cultures for efficient batch fermentation of glucose and xylose mixtures. Biotechnol Bioeng. 2011;108(2):376-85.

18. Hjersted JL, Henson MA, Mahadevan R. Genome-scale analysis of Saccharomyces cerevisiae metabolism and ethanol production in fed-batch culture. Biotechnol Bioeng. 2007;97(5):1190-204

19. Varma A, Palsson BO. Stoichiometric flux balance models quantitatively predict growth and metabolic by-product secretion in wild-type Escherichia coli W3110. Appl Environ Microbiol. 1994;60(10):3724-31.

20. Mahadevan R, Edwards JS, Doyle FJ. Dynamic flux balance analysis of diauxic growth in Escherichia coli. Biophys J. 2002;83(3):1331-40.

21. Nagarajan H, Sahin M, Nogales J, Latif H, Lovley DR, Ebrahim A, et al. Characterizing acetogenic metabolism using a genome-scale metabolic reconstruction of Clostridium ljungdahlii. Microb Cell Fact. 2013;12:118.
22. Younesi H, Najafpour G, Mohamed AR. Ethanol and acetate production from synthesis gas via fermentation processes using anaerobic bacterium, Clostridium ljungdahlii. Biochem Eng J. 2005;27(2):110-9.

23. Harcombe WR, Riehl WJ, Dukovski I, Granger BR, Betts A, Lang AH, et al. Metabolic resource allocation in individual microbes determines ecosystem interactions and spatial dynamics. Cell Rep. 2014;7(4):1104-15.

24. Fang Y, Scheibe TD, Mahadevan R, Garg S, Long PE, Lovley DR. Direct coupling of a genome-scale microbial in silico model and a groundwater reactive transport model. J Contam Hydrol. 2011;122(1-4):96-103.

25. Jayasinghe N, Franks A, Nevin KP, Mahadevan R. Metabolic modeling of spatial heterogeneity of biofilms in microbial fuel cells reveals substrate limitations in electrical current generation. Biotechnol J. 2014;9(10):1350-61.

26. Gomez JA, Höffner K, Barton PI. DFBAlab: a fast and reliable MATLAB code for dynamic flux balance analysis. BMC Bioinformatics. 2014;15:409.

27. Gaddy JL, Arora DK, Ko CW, Philip JR, Basu R. Methods for increasing the production of ethanol from microbial fermentation. US Patent Application 7285402 B2.

28. Munasinghe PC, Khanal SK. Syngas fermentation to biofuel: evaluation of carbon monoxide mass transfer coefficient $(\mathrm{k}(\mathrm{L})$ a) in different reactor configurations. Biotechnol Prog. 2010;26(6):1616-21.

29. Kantarci N, Borak F, Ulgen KO. Bubble column reactors. Process Biochem. 2005;40(7):2263-83.

30. Drake HL, Gossner AS, Daniel SL. Old acetogens, new light. Ann Ny Acad Sci. 2008;1125:100-28.

31. Bouaifi M, Hebrard G, Bastoul D, Roustan M. A comparative study of gas hold-up, bubble size, interfacial area and mass transfer coefficients in stirred gas-liquid reactors and bubble columns. Chem Eng Process. 2001;40(2):97-111.

32. Prakash A, Margaritis A, Li H, Bergougnou MA. Hydrodynamics and local heat transfer measurements in a bubble column with suspension of yeast. Biochem Eng J. 2001;9(2):155-63.

33. Joshi JB, Sharma MM. Circulation cell model for bubble-columns. TI Chem Eng-Lond. 1979;57(4):244-51.

34. Bredwell MD, Srivastava P, Worden RM. Reactor design issues for synthesis-gas fermentations. Biotechnol Prog. 1999;15(5):834-44.

35. Linstrom PJ, Mallard WG. NIST Chemistry WebBook, NIST standard reference database number 69. Gaithersburg MD: National Institute of Standards and Technology; 2015.

\section{Submit your next manuscript to BioMed Central and take full advantage of:}

- Convenient online submission

- Thorough peer review

- No space constraints or color figure charges

- Immediate publication on acceptance

- Inclusion in PubMed, CAS, Scopus and Google Scholar

- Research which is freely available for redistribution

Submit your manuscript at www.biomedcentral.com/submit
C) Biomed Central 